A wider understanding of mathematics might spare us the spectacle of statistics expressed in tenths of a per cent on data obtained by interviewing thirtynine people. Or the advertising absurdity "a reduction of up to thirty per cent less. ...."

These are little things, but they are signs of fuzzy thinking-and that means dangerous thinking. Perhaps there is a place somewhere for a scholarly study on mathematics as a vehicle-or at least a touchstone-of communication.

\title{
C. HIGH-SCHOOL-COLLEGE \\ CO-OPERATION IN DETERMINING MATHEMATICS REQUIREMENTS
}

\section{Phillip S. Jones}

$\mathrm{Q}$ UOTATIONS from a recent curriculum bulletin indicate two of the four basic problems of high school-college co-ordination in the field of mathematics. These are: "The specification by the colleges of certain high-school courses to be taken by all students seeking college entrance sets definite limitations to curriculum revision. ..." and "In no case should the college be expected to establish programs at a pre-college level in order to develop in students those learnings that make for success in college." 1

The third and fourth problems are those of providing for the needs of the nation and of the individual students. For the nation, progress in peace and defense and in science and society has never before been so closely allied with a supply of mathematically trained personnel capable of understanding, operating, and extending not only the notions of classical mathematics, but also new concepts and applications which are coming faster and faster. Since arguments of this type have appeared in many places and since data on the vocational aspects of mathematics have been presented elsewhere in this series of chapters, here we will merely name as an example of recently developed fields requiring collegiate mathematical background some of the short courses which were taught in the 1953 Summer Institute on Mathematics for Social Scientists sponsored by the Social Science Research Council: sets and relations, probability including stochastic process, matrix theory, theory of games, linear programming, and matbematical models in the social sciences. If psychology, economics, and sociology are moving into such mathematics (not merely statistics), how much more is now being

1 New College Admission Requirements Recommended. A Proposal for Cooperative Action by tbe Secondary Schools and Colleges in Illinois. Circular Series A, No. 51, Illinois Secondary-School Curriculum Program, Bulletin No. 9, January, 1951, pp. 5, 6.

Philip S. Jones is Associate Professor of Mathematics and the Teaching of Mathematics at the University of Michigan, Ann Arbor, Michigan. 
demanded in engineering and the physical science-even at their more elementary levels! Not only must persons with abilities of this type be located, and interested, but also they must be properly guided in order that their development may be as efficient as possible. However, it is not high-pressure recruitment that is needed, but a sound program which helps individuals to progress as they are able and to discover fascinating interests and opportunities of which they may not even become aware if left entirely to their own devices.

In fact, one facet of these national-good and individual-welfare guidance problems is that few pupils, parents, and even counselors are fully aware of the number of college programs which require some preparatory (secondaryschool level) mathematical background. Since few colleges now require highschool mathematics for admission, and even fewer require it for graduation, non-mathematicians lose sight of the fact that many special curricula within college can be pursued by mathematically unprepared students only after time and money are spent upon "make-up" work, if at all. Only careful and detailed reading of college catalogues will reveal all of these hidden requirements, but a recent series of studies in three midwestern states show that college curricula can be roughly divided into three categories: ${ }^{2}$

Class I. Matbematics not a prerequisite: English, foreign language, history, theology, music, art, physical education, and journalism. However, in one school students of journalism were required to study accounting and statistics; in another, those preparing for the ministry studied business and church architecture; while several departments of art recommended geometry.

Class II. College mathematics required (this, in general, implies some previous highschool work). Everyone recognizes that engineering and the sciences (even some areas of botany, zoology, and geology) fall into this category. Many would add business administration and agriculture. Perhaps fewer would include (as they should for a person majoring in the field) economics, forestry and conservation, psychology, sociology, public health, and architecture and design.

Class III. Matbematics required indirectly. These generally are curricula such as medicine, dentistry, medical technician, nursing, and pharmacy where mathematics is required implicitly as a prerequisite to the chemistry or physics which is listed explicitly. Hidden requirements even appear occasionally in such remote areas as dramatics (in connection with the physics required as a background for the study of stage lighting and sound amplification) and speech correction (in connection with the pre-medical work required as a basis for understanding speech abnormalities).

These prerequisites as well as those for collegiate mathematics courses are usually stated in terms of high-school algebra and geometry. This has been interpreted by some as a collegiate restriction on high-school curriculum experimentation. However, these words are merely convenient and customary titles derived from the high-school curriculum itself. The real desiderata are understanding of and some competence in several related areas of mathe-

\footnotetext{
"Edwards, P. D.; Jones, P. S., and Meserve, B. E., "Mathematical Preparation for College," $T$ tbe Matbematics Teacber. Vol. XIV, 1952, pp. 321-330. Copies are available at 15 cents each - from the National Council of Teachers of Mathematics, 1201 Sirteenth Street, N. W., Washing$\operatorname{con} 6$, D. C.
} 
matics. In what courses, carrying what titles, and at what grade level these are taught are irrelevant details to colleges as long as they are acquired by the students. In fact, several universities have recognized this explicitly. One engineering school, for example, has rephrased its graduation requirements in terms of competencies rather than hours of credit in mathematics. Another one, at least, has published a list of mathematical needs ${ }^{3}$ and explicitly encouraged experimentation with a unified or integrated mathematics program in its own campus high school. Such programs should not "set a limitation to curriculum revision" but should stimulate it!

There will continue to be problems in this area, of course. General mathematics listed on a high-school transcript, with no explanation, will be suspect in itself and of little value to college counselors in their placement of students. This is because it has in so many schools, for so many years, meant mathematics of low quantity and quality for inept and disinterested students. It may be necessary to enclose a dittoed note with transcripts explaining that credit equivalent to algebra and geometry, and perhaps even more, was earned in an integrated course. Perhaps a summary outline of mathematics I, II, III, IV, were these the names of new courses, should be included with the transcript.

One must also admit that there is still pressure upon the high schools to teach some mathematics. In this, however, the college is merely the agency of our national, social, and individual needs which speak through course requirements.

Here we come to the problem posed by the second part of our initial quotation, "In no case should the college be expected to establish programs at a pre-college level. ..." This is subject to both interpretation and debate. A number of colleges are now teaching begining high-school algebra and geometry; a few even give credit for these courses. In the latter cases, the student's total achievement upon graduation may be lessened by the time required for such elementary work, while if no credit is given, he will be burdened by additional work, or perhaps by summer session expenses. Less important than these disservices to our individual students, but still not negligible, are the burdens passed on to the colleges by such postponements. They must support and staff more classes, guide more students into more complicated sequences, and use the energies of hard-to-obtain collegiate teachers at levels of instruction for which their experience suits them less well while failing to utilize their specialized knowledge for advanced instruction and research.

All of this means that the essential elements of college preparatory mathematics should be highly recommended to all competent high-school

- Matbematical Needs of Prospective Students at the College of Engineering at the University of Illinois, Urbana, Illinois. University of Illinois Bulletin, Vol. 49, No. 9, September, 1951. 
pupils-not merely to college preparatory pupils. This is true because more and more students change their minds about further study, and many who do go on are uncertain of their areas of major interest or change their minds after a period in college.

This recommendation, however, would be of doubtful value for the welfare of secondary-school students as a whole were it not for the fact that substantially all of one to two years of college preparatory work can be of both value and interest to such students. Please, however, note the italicized can. This is not a blanket recommendation of a year of algebra and a year of geometry for all high-school students, not even, unreservedly, for all competent non-college directed students. For such a recommendation to be valid, high-school teachers and administrators must accept a responsibility. for revitalizing the content and methods used in these two years. Meaningless drill and excessive manipulation, wherever they exist, must give way to the teaching of significant mathematics for understanding and transfer. This teaching should emphasize the nature of logical reasoning and problem solving, and be accompanied by enrichment materials including genuine applications. This is a diffcult ideal toward which to strive, but progress is being made. New syllabi stressing an integrated program which is cognizant of both the power and sequence of mathematics as well as the immediate and long-run needs of students are being developed, some with the very deep involvement of college departments, as in the Illinois project and the work of the School and College of Admission with Advanced Standing. However, new and radically changed courses are not the essential element in improvement of instruction. Alert, vigorous, and informed teachers are, within the classical course organization, trying with increasing success to teach for transfer by stressing understanding, applications, and interrelationships.

However taught, mathematics is essentially sequential, especially in its early stages. In fact, properly exploited, this is one of its educational values. It is the area above all others where lack of high-school preparation retards college progress both in the same field and in numerous related areas. Hence the extra importance in this area of proper counseling and of guaranteeing an opportunity to elect substantial mathematical work during one's high-school years.

Where double or even triple track programs can be maintained in mathematics at the ninth- (and perhaps tenth- and twelfth-) grade levels, there is much to be said for them, but such integrated courses as were suggested above may enable the small high school to offer ninth- and tenth-grade mathematics adequate for college preparatory students which also is functional for all others of at least normal competence. For later and more specialized college preparatory courses, the small school may make use of cycling of 
sourses in the eleventh and twelfth years as well as correspondence courses, preferably school financed and supervised.

By way of recommendations to administrators in regard to the mathematical preparation for college, we summarize as follows:

1. Be sure that counseling conveys to students a recognition of the increasing variety of areas of college study requiring some high-school level mathematical preparation, either implicitly or explicitly.

2. Assist and encourage teachers to revitalize the content, materials, and methods of mathematics teaching. Such help and encouragement may include providing: (a) money for teaching aids and materials; (b) time and expense money for attending conferences and working with committees studying such problems; (c) a teaching load which allows time for planning, experimentation, and evaluation; and (d) encouragement and moral support in such endeavars.

3. Provide a full mathematics program for interested and able students even in small schools, if necessary, by cycling courses and using correspondence study.

4. Encourage teachers to make a frontal attack upon the problem of recognizing, stimulating, and guiding the really superior student, a problem discussed in more detail elsewhere in this publication. However, advanced course work (e.g., calculus) for a very few should not be sought at the expense of a firm foundation in the understanding of basic concepts.

\section{THE LEARNING OF MATHEMATICS}

\section{Its Theory and Practice \\ Twenty-First Yearbook of the \\ National Council of Teachers of Mathematics}

This yearbook applies the most recent discoveries concerning the nature of the learning process to the problems of the mathematics classroom.

The very large sale that this yearbook has enjoyed since its publication in January 1953 indicates that it fills a definite need in the teaching of mathematics.

Authorities consider it a significant contribution to the literature in mathematics education.

This book discusses many questions about drill, transfer of training, problemsolving, concept formation, motivation, sensory learning, individual differences, and other problems.

Price, postpaid, $\$ 4.00$. To members of the Council, $\$ 3.00$. Please send remittance with order.

NATIONAL COUNCIL OF TFACHERS OF MATHEMATICS 1201 Sixteenth Street, N.W.

Washington 6, D.C. 